\title{
Arte y poesía sobre los rieles del archivo. Un ramal que conecta territorios y comunidades
}

MARÍA EUGENIA RASIC Universidad Nacional de La Plata, Argentina / mariaeugeniarasic@gmail.com MERCEDES RESCH; NILDA ROSEMBERG; VERÓNICA SUANNO Proyecto Hermosura, Argentina / mercedesresch@hotmail.com / rosnil70@hotmail.com / verosuanno@hotmail.com

\section{Resumen}

El siguiente trabajo se propone establecer un contacto entre dos territorios de la provincia de Buenos Aires que, si bien nunca han estado conectados directamente por algún ramal del ferrocarril, sí habrán de estarlo a partir de la lectura hecha desde el archivo respecto a las acciones poéticas y artísticas desarrolladas por la comunidad que habita en estos puntos del mapa. Dichas acciones, las cuales cuentan con una potencia de archivo arrolladora, se han llevado a cabo, y muchas de ellas aún continúan, en el marco de los siguientes proyectos culturales: Estación Pringles, localizado principalmente en las estaciones del Partido de Coronel Pringles, y Proyecto Hermosura, localizado en la estación de Cura Malal, Partido de Coronel Suárez. Como verán a continuación, la mirada archifilológica puesta sobre las acciones poéticas, artísticas y colectivas, desplegadas en el territorio y el paisaje que lo compone, recuperará ante vuestros ojos los chispazos del tren que por allí pasaba, así como también, los destellos de una comunidad latente e inapropiable.

Palabras clave: archivo / arte y poesía / comunidad / territorio / tren

\section{Art and poetry on archive rails. A branch line that connects territories and communities \\ Abstract}

The next article proposes to establish a contact between two territories of the province of Buenos Aires that, although they have never been directly connected by any branch of the railroad, they should be from the reading made from the archive regarding the poetic actions and artistic developed by the community that lives in these points of the map. These actions, which have an overwhelming archival power, have been carried out, and many of them still continue, within the framework of the following cultural projects: Estación Pringles, located mainly in the stations of the Party of Colonel Pringles, and Proyecto Hermosura, located at the Cura-Malal station, Partido de Coronel Suárez. As you will see below, the archifilological look on the poetic, artistic and collective actions, deployed in the territory and the landscape that composes it, will recover before your eyes the sparks of the train that passed through there, as well as the flashes of a latent and inappropriate community.

Key words: archive / Art and poetry / community / territory / train

Recibido: 17/6/2019. Aceptado: 16/8/2019

Para citar este artículo: Rasic, M.E.; Resch, M.; Rosemberg, N. y Suanno, V. (2019). Arte y poesía sobre los rieles del archivo. Un ramal que conecta territorios y comunidades. El taco en la brea, 10 (junio-noviembre), 150-160. Santa Fe, Argentina: UNL. DOI: 10.14409/tb.v1i10.8695 
Este artículo está escrito por un colectivo de cuatro autoras y, por ende, aparecerán en éste cruces de miradas, palabras, prácticas y disciplinas que, como las vías del ferrocarril, se ponen a conectar no sólo puntos distantes en el espacio, sino también objetos, saberes, experiencias, tiempos, paisajes, voces y personas. Es a partir del armado de estas conexiones heterogéneas que los proyectos poéticos, artísticos y documentales a estudiar posibilitan el espacio desde el cual nos ponemos a pensar los modos de construir archivo, historia, memoria y comunidad en un territorio delimitado a la provincia de Buenos Aires; $y$, a la vez, los modos en que dichos proyectos configuran, también con su potencia de archivo irreductible, una comunidad de afinidades (Cusicanqui, 2015) con sus propias, aunque más bien colectivas, lógicas de intercambio y de conservación (Bataille). Nos referimos específicamente a Estación Pringles, proyecto poético y artístico fundado en el año 2006, en la localidad de Coronel Pringles, y a Proyecto Hermosura, proyecto poético documental nacido en el año 2007, en el pueblo Cura Malal, Partido de Coronel Suárez. La idea es entonces presentar ambos proyectos y pensar cómo con el despliegue de sus prácticas en un territorio atravesado fuertemente por los relatos del desierto y por políticas económicas que propulsaron el aislamiento de los lugares y de la gente es posible construir una noción del archivo que emerge, por un lado, tanto de los registros escritos y audiovisuales guardados como de los que se hallan dispersos a la espera de su organización y lectura crítica. Por otro lado, una noción del archivo vivo que emerge también de la falta y de los restos en el paisaje rural del mapa bonaerense. En ambos casos, una noción del archivo que emerge de un hacer comunitario que preserva a los lugares y a la gente de su invisibilidad cartográfica y de su desaparición.

Tomemos ahora el tren de la noche y vayamos a la primera estación: Coronel Pringles (37 59' Lat. Sur; $61^{\circ} 22^{\prime}$ Long. Oeste - Pcia. de Buenos Aires). Allí la poesía y el arte a cielo abierto recuperan ante nuestros ojos la presencia de las luciérnagas que, como nos recuerda Didi-Huberman a partir del cine de Pasolini, con el exceso de luz de la gran ciudad, no logramos ver. Esas luciérnagas serán también en este trabajo "una comunidad de centinelas» que, gracias a la fuerza de lo colectivo, transformó el poema en marcha en el tren de la historia (Carrera, 2008). Subidas a este tren entonces, las y los invitamos a bajarnos en la primera estación.

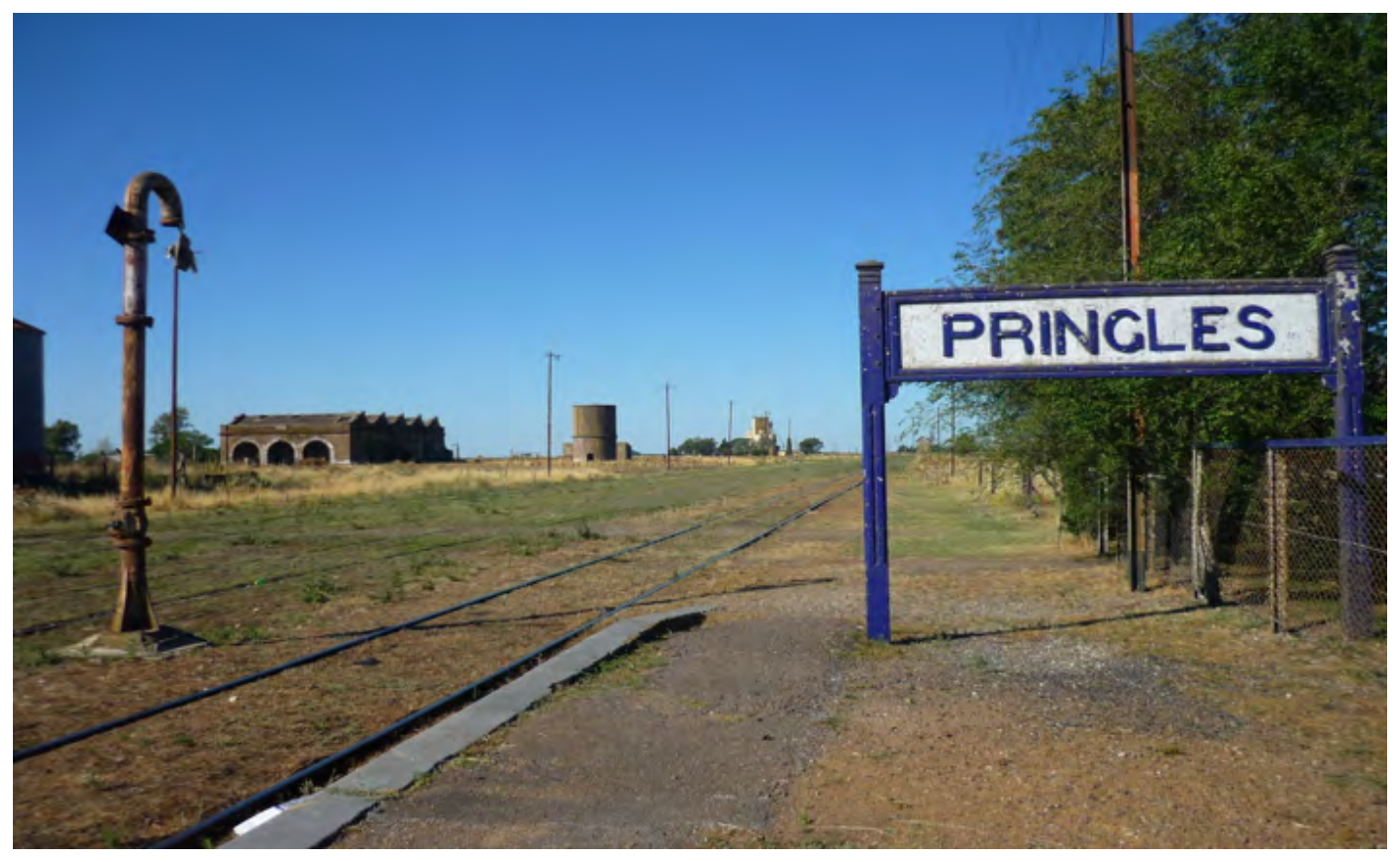




\title{
Estación Pringles: la poesía en marcha
}

\author{
Lartigau \\ Me despierto. Es muy temprano aún. \\ Espero el canto del gallo. \\ Lo escuché en un gradiente de la noche \\ que parecía lejano. Sin embargo, \\ tan sonora y minuciosa era su forma de llamado... \\ pero, \\ ¿llama un gallo? ¿Se dirige a cada uno \\ o a su comunidad de centinelas? \\ ¿Define en la certeza alguna duda \\ o llena de incertidumbre el desvelo incipiente? \\ (Carrera, 2008:13)
}

Con este poema comienza el libro Las cuatro estaciones de Arturo Carrera, editado en el año 2008 por Mansalva. El mismo se encuentra estructurado en cuatro partes cuyos nombres hacen referencia explícita a cuatro estaciones del partido de Coronel Pringles, lugar en el que el poeta nace y escribe, más a las cuatro estaciones del ciclo de la naturaleza: Lartigau (Primavera), Quiñihual (Verano), Pringles (Otoño), Krabbe (Invierno). En el comienzo de cada una de ellas podemos leer una breve reseña hecha por el autor sobre las coordenadas geográficas, históricas y demográficas de cada una de esas estaciones. Los datos reales que allí encontramos respecto al desmantelamiento poblacional y cultural de las estaciones se hacen eco en cada uno de los poemas que constituyen el libro, en cada canto del gallo, árbol, rana o grillo solitario que, si bien son también resonancias poéticas de un amplio trayecto poético del autor (Rasic), aquí construyen un efecto acústico desolador y ya no tanto metafórico del vacío. En «Quiñihual» leemos: «Aquí tampoco hay nadie/ Aquí tampoco hay nadie./ Es como el rastro que el rastreador dibujara/ el vestigio de un cuento que no supimos comprender/y ahora es nuestra biografía» (Carrera, 2008:47).

Dos años antes de que este libro saliera a la luz, el autor ya había comenzado una investigación exhaustiva sobre las estaciones de ferrocarril en el Partido de Coronel Pringles y alrededores. Y, como bien señala Daniel Link en el epílogo del poemario, esos lugares habitados por los fantasmas de la infancia del poeta le dijeron al oído sus anhelos secretos y lo contagiaron de una fuerza poética que le permitió a Carrera, junto con otros artistas y colaboradores, transformar lo imaginario en realidad y la poesía en acción: la creación de una sociedad llamada «Estación Pringles» capaz de recuperar «esa parte de nosotros que habíamos dejado que se nos escapara como arena en el viento» (Link:109). Las antiguas estaciones de ferrocarril, ya para los años dos mil desactivadas para su uso público, volverán a existir por (y para) el arte y por (y para) el pueblo. Una forma de descentramiento pero, sobre todo, nos vuelve a decir Daniel Link, una forma de hacer política. Aunque también agregamos: una forma de hacer archivo y una forma de hacer comunidad.

Es así como en el año 2006 se crea Estación Pringles, un proyecto de plataforma poética y artística desarrollado en el territorio de Coronel Pringles que comprende, tal como el libro de poemas lo señala, pequeñas estaciones de ferrocarril en las que no sólo el tren por allí pasaba y conectaba con un centro (siempre Buenos Aires), sino además, pequeñas estaciones en las que las personas a su alrededor 
habitaban. Fundado por los escritores Arturo Carrera, César Aira, los artistas visuales José Cambre y Alfredo Prior y la gestora cultural Chiquita Gramajo, Estación Pringles consistió, y lo enunciamos en pretérito porque el proyecto dejó de ejecutarse en el año 2015 principalmente por falta de recursos económicos para su mantenimiento, en la reactivación justamente de dichas estaciones, no ya mediante la maquinaria del tren, tarea que supone una política económica de intervención por parte del Estado, sino mediante la poesía y el arte en manos de un conjunto heterogéneo de personas: kermesses, concursos de manchas, murgas, justa de payadores, caravana de declamadoras, muestra de poesía ilustrada, recitales, encuentro de artistas, traductores y escritores, talleres de escritura dictados por escritores reconocidos para las maestras rurales, residencia para escritores nacionales e internacionales, intervenciones artísticas en zonas rurales y en edificios de Francisco Salamone, concursos literarios, ediciones de libros de poesía, visita de docentes y estudiantes universitarios con fines académicos y recuperación de espacios colectivos y con memoria histórica como la escuela rural $\mathrm{N}^{\circ}$ 21 de Quiñihual y la estación de trenes, hace años ya desafectados, como hemos venido insistiendo, para sus usos públicos. Respecto a esto último, es impactante pensar que mientras Estación Pringles restaura y recupera — acciones centrales para quienes trabajamos con materiales de archivo— una escuela rural abandonada, las políticas educativas llevadas a cabo en los años 2017-2018 por el gobierno de la provincia de Buenos Aires ordenaron cerrar más de 40 escuelas rurales por ser consideradas un «gasto público» innecesario en relación con la cantidad de alumnas y alumnos asistentes.'

No sólo quienes trabajamos en y con determinados objetos, ámbitos y comunidades podemos atestiguar que las políticas de desguace comienzan siempre por las zonas más «invisibles» y alejadas del «centro» respecto a la mirada dominante, sino que también construyen una noción de "gasto improductivo» que el trabajo con archivos y otros bienes culturales, pero fundamentalmente con archivos, transforma en "potlatch»:2 creación por medio de la pérdida y, hasta inclusive, del derroche (Bataille). Porque si bien, nos dice Derrida, para que haya condición de archivo debemos exponernos a la idea y a la tarea concreta de la falta y del olvido (233), el archivo comunitario que estas acciones artísticas y poéticas construyen se sostiene

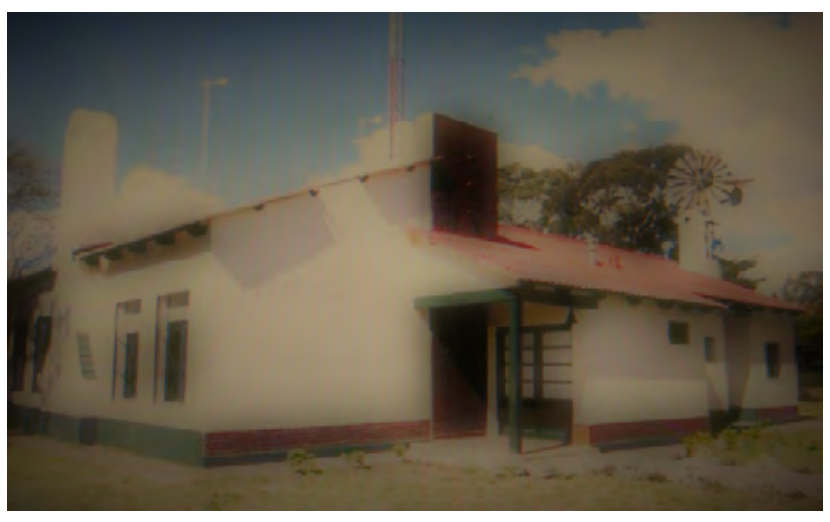

Escuela pública ํo 21 de Quiñihual convertida en centro de residencias para escritoras y escritores en el marco del Proyecto Estación Pringles tanto por lo que conservan —en la materialidad de los registros y en la materialidad de la memoria colectiva - como por lo que pierden en su puesta en común y en su fugacidad, puesto que funciona allí una lógica del don y del intercambio — de objetos, de saberes, de experiencias — que expone a sus hacedores a un deshacerse de y a un despojo permanente y necesario para que haya condición de archivo, pero también, para que la comunidad resista y permanezca. El arte y la poesía puestos en acción territorial y comunitaria ocurren y acontecen, pues, en «un flujo espiritual desgarrador y decisivo entre donatarios y donadores» (Carrera, 2004:19). ¿Qué es lo que se pone en juego en estas acciones además del cuerpo, la voz, la palabra en su dimensión oral y escrita? ¿Qué es lo que los sujetos allí intercambian y dan sin retener para sí más que una experiencia con otros sujetos en el presente fugaz, aunque perdurable a la vez, en el archivo de la memoria colectiva? En esta pregunta lo que subyace latente, junto con el pulso del tren, es el tiempo que, como en la poesía, marca el ritmo, tanto de la escritura como de la vida, y vale oro: 


\author{
Ahorro, derroche, \\ ¿qué se va de tu boca como palabra y \\ entra en tus manos como plata, monedas, \\ oh,
}

eco de niño?

(Carrera, 2004:43)

Además de contar con una potencia creativa arrolladora, capaz inclusive de arrancar a la poesía y al arte de una fuerte tradición escrita, gráfica, museística y, principalmente, individual, las acciones desarrolladas en Pringles (como así también, ya verán, las acciones desarrolladas en Cura Malal) cuentan con una potencia de archivo que nos interesa destacar, puesto que, por un lado, sus registros escritos y audiovisuales se hallan dispersos, en la web o en el acervo de sus coordinadores, a la espera de su organización y sistematización crítica; por otro lado, porque estos registros construyen una memoria intermitente activa y reaniman una historia viva en los territorios y en los paisajes donde, como dice el poema, sobrevive aún «el vestigio de un cuento que no supimos comprender/y ahora es nuestra biografía». Consideramos que esta lectura desde la potencia de archivo es necesaria y «urgente» (Antelo) porque permite colocar la mirada allí donde todo pareciera haber desfallecido y porque, por el contrario, detecta en los rastros del lugar y de la historia que las acciones poéticas y artísticas recuperan, una fuerza transformadora capaz de poblar los relatos del desierto y de la llanura bonaerense (Rodríguez; Arzac y Stedille) de encuentros, saberes, espacios y tiempos comunitarios que han sido y que, lo que más nos importa a fin de preservar la comunidad de su desaparición, están por venir. Esta es también la potencia del archivo: la de pensar nuestros objetos y los lugares con una temporalidad incierta y, por ello mismo, siempre futura, porque, desde la mirada del archivo, algún día el porvenir hará historia y el tren, como maquinaria colectiva, volverá. El triunfo de lo común es y será desde siempre inapropiable.

\section{Proyecto Hermosura: una experiencia de la experiencia}

Desde el andén 14 de Constitución sale el tren que recorre parte de la provincia de Buenos Aires, en el que veníamos viajando hacia el sur para llegar a Pringles. Pero es a mitad de camino, en Olavarría, que se dividen los ramales y se opta por una vía o la otra, o va vía Lamadrid o vía Pringles. Y es por eso que no comparten el mismo ramal en todo su recorrido: no hay vías de ferrocarril que conecten Coronel Pringles y Cura Malal. Sólo si optás por vía Lamadrid pasarás, luego de unas horas, por Cura Malal. No obstante, hay un paisaje que hermana esas dos estaciones que, si bien no comparten un mismo camino desde la estación porteña, sí comparten un mismo destino y un andén que los conecta: la mirada desde el archivo y la comunidad. Así que en busca de esta posibilidad de construir archivo, de habitar colectivamente las memorias comunitarias, es que las y los invitamos volver hasta Olavarría, cambiar el carril y seguir viaje hasta la estación siguiente a Coronel Suárez, donde se localiza Cura Malal.

Transcurridas unas horas de mirar el horizonte amplio y la llanura, comenzamos a ver un cordón serrano. Estamos ubicados a 37,4667 grados de latitud y este es el contexto que nos recibe: 
Cura Malal, un pueblo ubicado en la zona oeste del partido de Coronel Suárez, a $20 \mathrm{~km}$ de la ciudad cabecera, cerca del arroyo Cura Malal Grande y a $3 \mathrm{~km}$ de la ruta provincial 67. Su nombre de origen araucano significa "corral de piedra» y la fecha estimada de fundación es el 17 de septiembre de 1905 cuando se trazó el primer tejido urbano de 48 manzanas. Las tierras del actual Cura Malal fueron cedidas por Eduardo Casey. Ya existían en ese entonces la estación de trenes del Ferrocarril del Sud, inaugurada 20 años antes, y la Escuela $\mathrm{N}^{\circ} 6$ que funciona de manera ininterrumpida desde el año 1889. El censo del año 2010 dio como resultado 94 habitantes, menos de un $10 \%$ de ese millar de pobladores que vivía en la localidad en la primera década del siglo XX, antes de la mecanización de las tareas agrícolas, la desactivación ferroviaria y la construcción de rutas pavimentadas. El grueso de la población estuvo ligado a las Estancias «La Curamalan» y «La Cascada».

Es desde este territorio que nos planteamos la siguiente pregunta: ¿se pueden pensar como archivo las acciones colectivas construidas desde una mirada poética-documental? Proyecto Hermosura es un proyecto desarrollado por Verónica Suanno, Nilda Rosembergy Mercedes Resch; tres mujeres, artistas, docentes y amigas que trabajamos juntas desde finales de 2007 con foco en esta territorialidad.Desdesuinicio,esteproyectoproponegenerarunareflexiónapartirdelencuentroconlarealidad de algunas comunidades rurales del sudoeste de la provincia de Buenos Aires. Durante la primera etapa de trabajo, los encuentros consistieron en una serie de visitas, de aproximaciones al universo de estas personas situadas en su contexto. Los registros audiovisuales sirvieron de documentos -escucha y memoria del encuentro, relatos-; la traducción a un lenguaje poético y la utilización de recursos visuales, escritos, sonoros, espaciales, son las herramientas que utilizamos para crear y poner en valor una suerte de archivo vivo. Archivo resultante de la experiencia de unir lo documental con lo poético, entendiendo como fundamental la importancia del paisaje como producto de la cultura de los habitantes y como causante de las especificidades que conforman la hermosura del lugar. Encontrar cuáles son sus haceres cotidianos, cómo resuelven una problemática particular, qué diálogos establecen entre su presente y su pasado. Estamos documentando nuestra propia experiencia de la visita, del trabajo en grupo: la experiencia de trabajar con la experiencia.

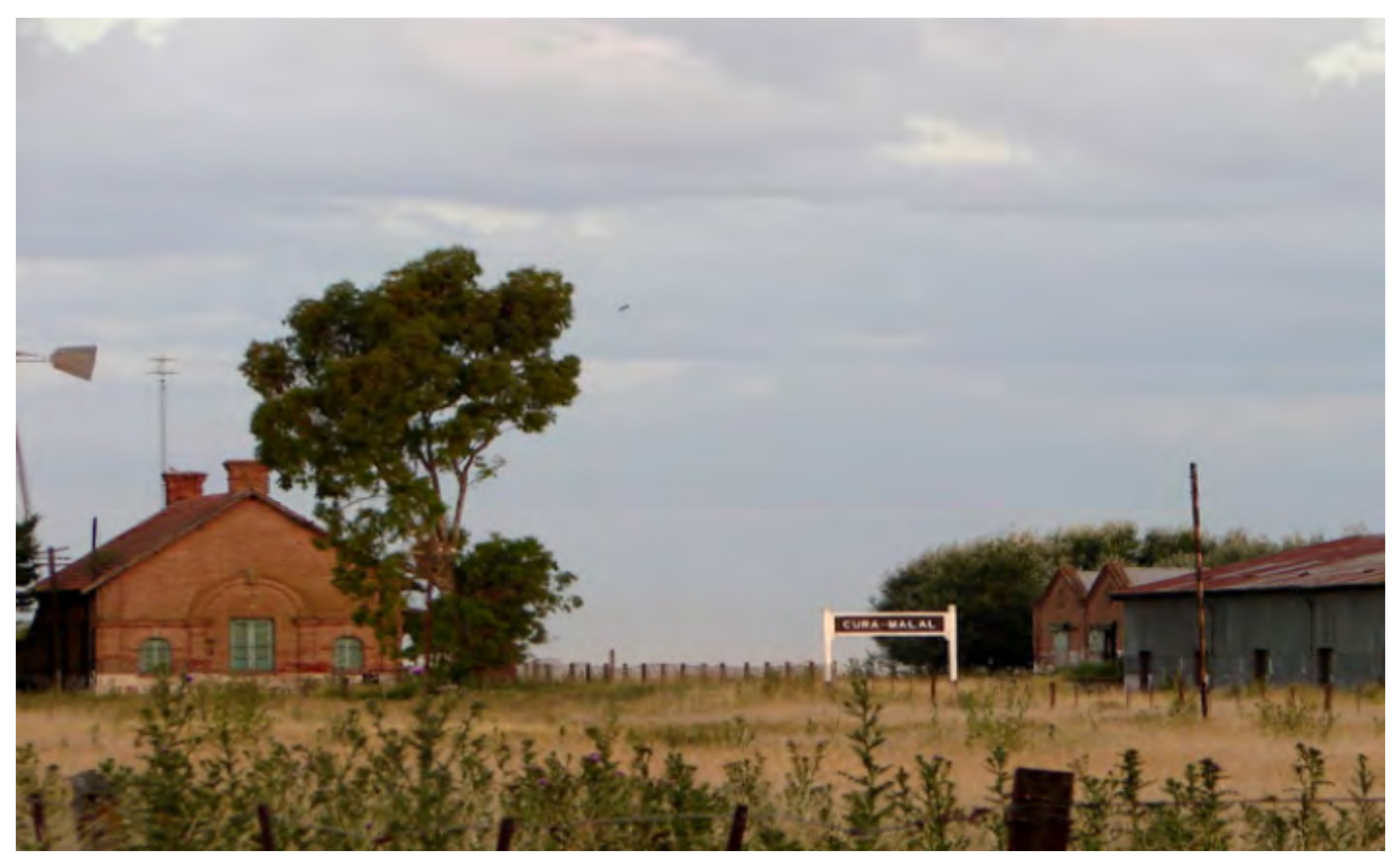


Para responder a la pregunta que planteamos más arriba — la posibilidad de pensar las acciones colectivas construidas desde una mirada poética-documental como archivo- proponemos recuperar dos experiencias realizadas en el pueblo en momentos y contextos diferentes. Nos enfocamos en ellas desde una mirada retrospectiva y a partir de algunos conceptos que propone la geografía de la percepción. Es decir, entendemos que el modo de mapear o percibir el espacio de cada habitante, es la construcción de una subjetividad. Nos interesa, entonces, poder compartir la acción a partir de la construcción de un mapa mental. Para ello vamos a invitar a las y los lectores a realizar un ejercicio breve que consiste en la elaboración de un mapa mental del territorio que habitan, graficando de modo simple cuáles son los hitos que encuentran en su espacio, cuáles son los trayectos que realizan entre ellas y ellos y cuáles son los espacios que funcionan como límites o bordes entre estos espacios.

El mapa mental que cada sujeto elabora depende de las vivencias que cada cual tenga con ese entorno urbano, sus recuerdos, los acontecimientos que se hayan producido en él y de los que tenga memoria, los elementos que importan en su vida, como su casa, su barrio, su espacio vivencial. Nos interesa pensar que es en función de esa percepción que muchos de nosotras y nosotros tomamos decisiones espaciales. Los elementos que conforman este mapa mental están interrelacionados entre sí, pero al mismo tiempo son cambiantes, es decir, el significado de ellas y ellos va a ser diferente según quién es la persona y cuál la circunstancia en la cual se encuentre. De este modo, estos mapeos van a construir imágenes subjetivas a partir de un territorio objetivo.

Luego de haber atravesado velozmente la práctica del mapa mental nos aventuramos a comentarles las experiencias que seleccionamos y les sugerimos que las «lean» a partir de su vivencia al realizar dicho mapa. La primera de las acciones elegidas sucedió en el marco de la presentación de Proyecto Hermosura a la comunidad de Cura Malal. Era una tarde de verano de 2009, después de casi un año de trabajo en territorio y previa a la realización de nuestra primera muestra en Coronel Suárez. Decidimos compartir lo sucedido primero con sus protagonistas. Pedimos prestadas mesas y sillas al club «Juventud Unida de Cura Malal», cortamos la calle, decoramos el espacio con banderines de colores e invitamos a la gente del pueblo y de las ciudades aledañas a acompañarnos. Había puestos de la escuela y del club que vendían comida, contábamos con un equipo de sonido y un proyector, y teníamos previstas una serie de actividades que, de modo lúdico, activaran la memoria y generaran una suerte de participación y de apropiación del pueblo por sus propios habitantes y por los visitantes.

Una de estas actividades consistió en brindar a todos los presentes una ficha que lograba su sentido al ser escrita y dibujada por ellos. La ficha tenía dos lados, uno donde aparecían preguntas en torno a los nombres de las calles de Cura Malal, a los animales que se pueden ver en el pueblo y a los árboles; y otra donde cada una y uno debía dibujar la fachada de su casa.

En la individualidad y en el conjunto, estas fichas construían una colección de datos y al mismo tiempo ac-
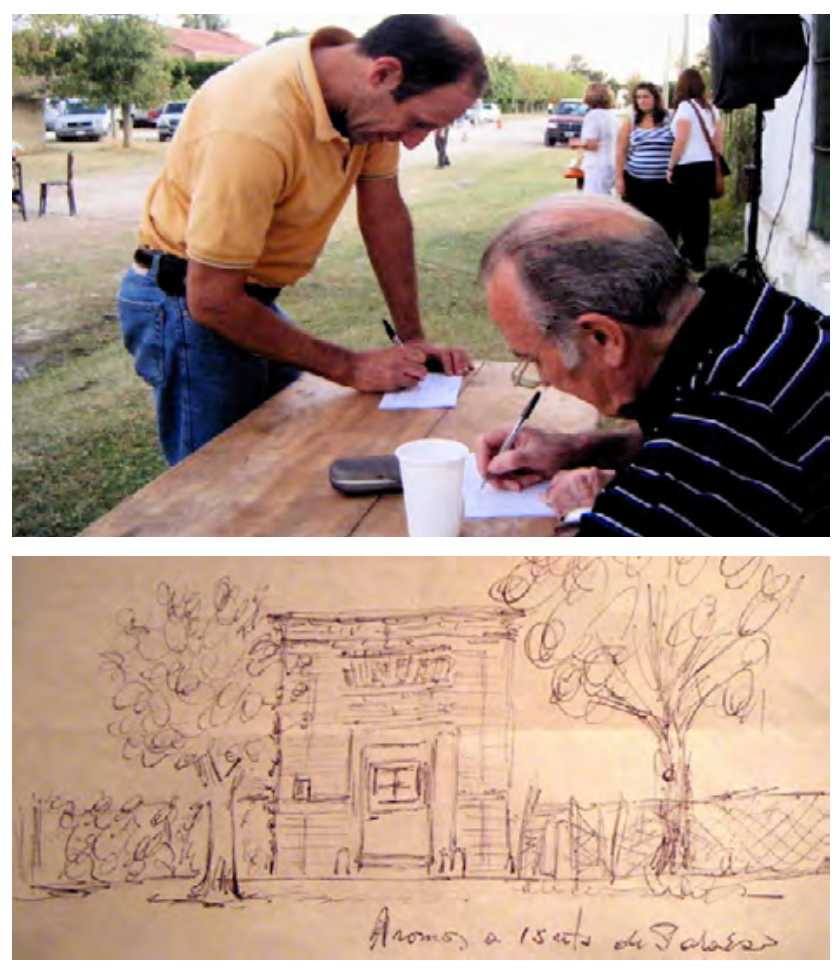

Participación de los vecinos de Cura Malal llenando las fichas durante la jornada de presentación del proyecto en el territorio (Año 2007) 
tivaban y actualizaban la memoria de quienes estaban ahí. Los datos no sólo eran cuantitativos, sino que traslucían y presentaban a través de los gestos de la escritura y del dibujo, vínculos y relaciones descriptivas tanto de lo afectivo como del concepto de tiempo-espacio.

¿Pero cómo dar cuenta de un paisaje sólo a partir de lo visual? Aparece entonces la idea de construir un paisaje sonoro del pueblo. Nos visita Javier Ortiz, músico y compositor que graba y edita una serie de fragmentos sonoros que fuimos encontrando juntos al compartir un día completo de trabajo en Cura Malal. Una vez realizada la pieza de audio, fuimos, con ayuda de varias vecinas y vecinos del pueblo, identificando los sonidos, distinguiendo los pájaros, las voces y los espacios donde estos habían sido registrados. Un mapeo sonoro, un archivo poético que documenta, nuevamente de un modo no tan formal, el acontecer de ese día.

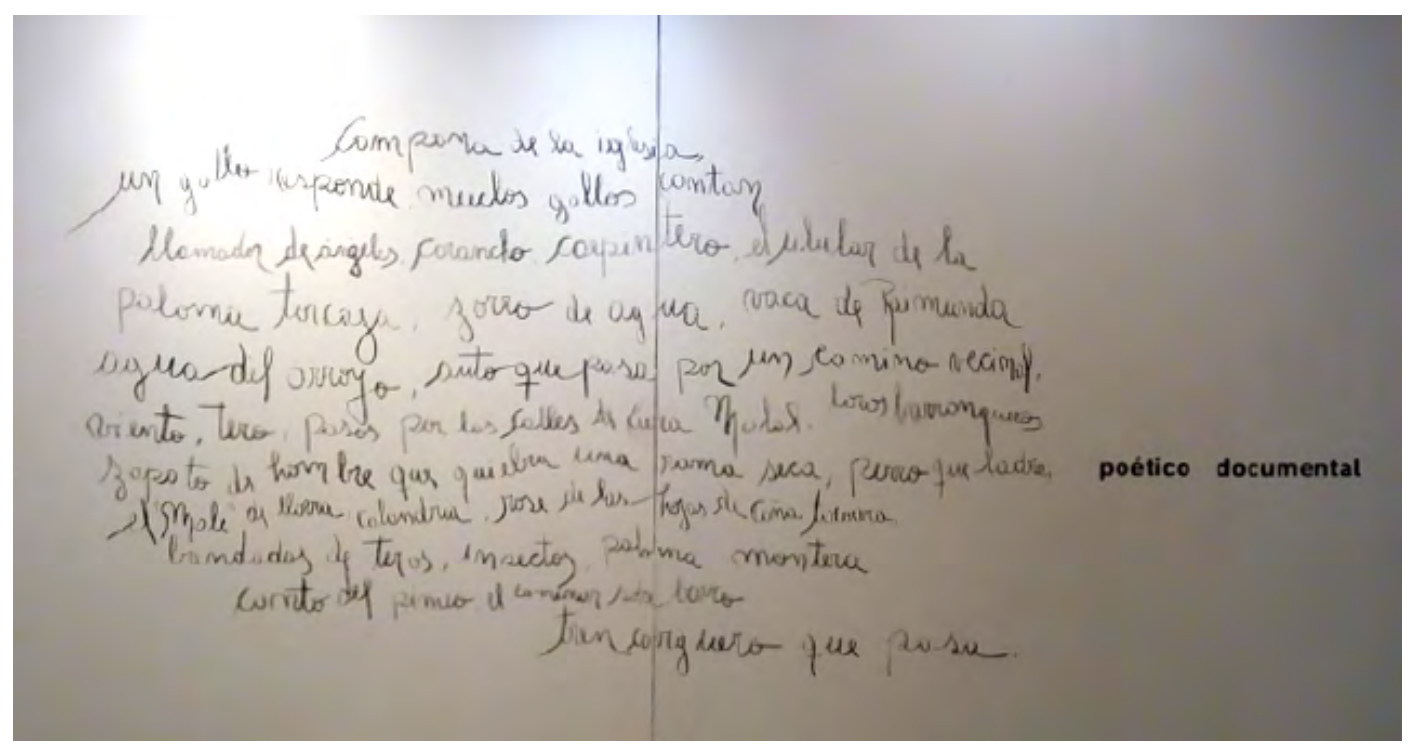

Casi diez años después y con motivo de repensar nuestra práctica y el deseo de continuar indagando este modo de estar en el territorio, sumamos a la comunidad del pueblo otra comunidad conformada por artistas que fueron parte de una residencia para hacedores llamada "Originario». Las residencias, que hasta el momento son dos, se realizaron en febrero de 2017 y 2018 . Por medio de una convocatoria abierta, se generaron dos grupos de artistas que traían saberes particulares. En «Originario» se proponía un cruce entre los orígenes de las producciones de cada uno de estos hacedores y el contexto. Las y los residentes generaron cruces que vincularon distintas temporalidades desde los pueblos originarios hasta los actuales habitantes de Cura Malal. La dinámica de las residencias estaba organizada de la siguiente manera: tres días de trabajo en territorio. Esos días comenzaban con un recorrido por el pueblo y con la guía de Mercedes, oriunda de allí, que vive y realiza sus prácticas desde La Tranca, espacio de arte que es el sitio físico que contuvo a los residentes. Actividades guiadas y grupales primero; espacios de trabajo individual después. Terminando el cuarto día con una jornada abierta a la comunidad en la cual además de compartir la experiencia sucedida en estos días, intercambiamos ideas con otros proyectos de arte y artistas de la zona que compartieron lecturas de poesía, muestras de fotografías, proyección de video, música en vivo entre otras cosas. Unos meses después organizamos una serie de muestras itinerantes compuestas por obras que los residentes realizaron a partir de sus experiencias en «Originario». El texto curatorial y el diseño de montaje de las muestras es un trabajo con el cual desde Proyecto 
Hermosura aportamos nuestra experiencia como organizadoras de la residencia y proyectamos también nuevas preguntas sobre el modo de recolectar, organizar y producir sentido a partir de documentos y experiencias. Pensamos en compartirlas como forma de seguir ampliando la pregunta inicial, de activar una relectura concreta sobre los espacios, las relaciones vinculares, las normas y trayectorias particulares.

\section{Entre las chispas del tren}

Si bien las acciones desarrolladas con Estación Pringles

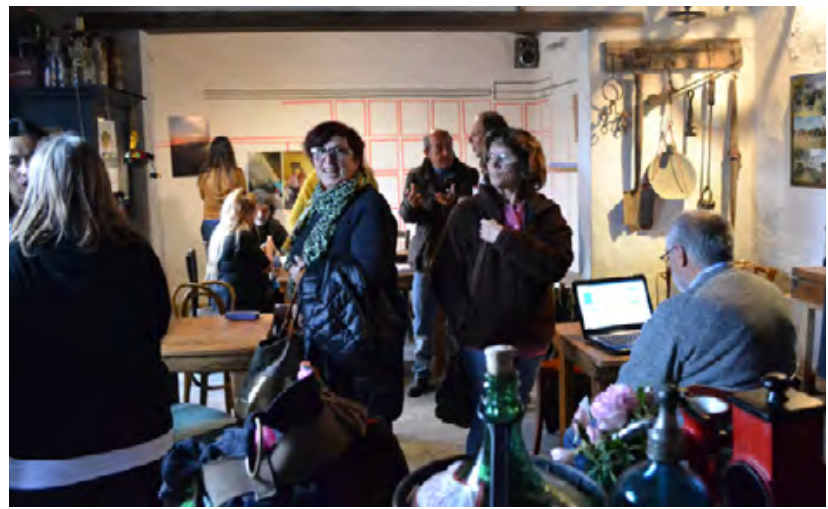

Muestra de la segunda residencia «Originario» en la pulpería La Tranca, Cura Malal, 2017 y Proyecto Hermosura pueden ser leídas como un núcleo intenso de estéticas emergentes, capaces de abrir canales de comunicación entre expertos y no expertos y producir objetos fronterizos mediante iniciativas de distinta índole (Laddaga), nos interesa además comenzar a leer y pensar críticamente las relaciones entre archivo y comunidad que se desprenden de dicho núcleo en comunidades específicamente rurales, antes que urbanas, y desde una perspectiva principalmente poética, artística y archifilológica (Antelo), ${ }^{3}$ las cuales se cruzan y transforman el chispeo resultante de ese cruce en las luciérnagas que las luces de la gran ciudad y del progreso siguen ocultando ante nuestros ojos, producto de un largo proceso de modernización nacional que ha instaurado en los pueblos rurales de la provincia de Buenos Aires tanto nombres como «desiertos» y fantasmas, mientras que en las grandes urbes ha instaurado numerosos habitantes, grandilocuentes construcciones, diversas instalaciones tecnológicas y una aletargada ceguera. Creemos, entonces, que la mirada desde la poesía, el arte y el archivo permite no solo el encuentro de elementos heterogéneos y de temporalidades con carriles alternativos al propuesto por el sentido teleológico que las iluminarias de la modernización nos han tendido, sino también permite la conexión de lugares, objetos, sujetos y experiencias que los ramales de la historia y los proyectos de organización territorial han mantenido en su transcurso aislados. Como ya hemos señalado, el tren que las pasajeras y los pasajeros podían tomar para llegar a Pringles y a Cura Malal, cuando este funcionaba para el uso público, parte de Buenos Aires hacia un destino y retorna de dicho destino hacia Buenos Aires. Este recorrido lineal y unidireccional, que es también un dibujo político hecho sobre el llano, despliega de manera autoevidente cuál es la mirada que domina, de manera particular, nuestros modos de seleccionar, organizar y nombrar nuestros objetos de estudio y, de manera general, nuestros modos de leer el archivo, la cultura y la historia. Aunque también, y en nuestro trabajo de esto se trata, condiciona nuestros modos de transitarlas. Porque leer y hacer archivo desde estas prácticas comunitarias es una forma de hacer territorio y de trazar nuevas rutas para que, por medio de la fuerza de la poesía y del arte, la comunidad no desaparezca. Coronel Pringles y Cura Malal pueden ser apenas el comienzo de una constelación sobre tierra más amplia.

Como hemos visto (o imaginado durante la lectura), la poesía, el arte y el archivo aguardan allí, en las acciones comunitarias realizadas sobre el territorio trazado y sobre un paisaje que también lo compone: el campo, las vías del tren siempre invisible, los animales, los sonidos del ambiente, el asomo de las sierras en plena llanura pampeana, los cielos de Pringles y de Cura Malal con sus figuras infinitas, los itinerarios que por allí se deslizan, los carteles y los mapas desgastados por 
el paso del tiempo y por su desuso, el ensamble móvil y dinámico de interacciones imprevisibles entre agentes humanos y no-humanos allí presentes (Andermann). La lectura de las conexiones entre las prácticas poéticas, artísticas y documentales, el territorio, los sujetos y los tiempos que allí conviven hallan en el chispeo de ese cruce la coexistencia de una comunidad de afinidades no solo entre actores y acciones culturales diversas, sino también entre pasados y presentes históricos que construyen espacios de lo común en los márgenes de las grandes urbes y en el tiempo de la simultaneidad y del anacronismo. Un tiempo en común que devuelve al sujeto un sentido mágico en el que el pasado no ha muerto y los trenes, por el arte de la palabra y de la imagen puesta en circulación y abierta a la intemperie, reaparecen para ser compartidos no ya desde la lógica por la cual el progreso mercantilista los ha puesto y sacado del andén, sino desde otras lógicas que hacen obra, acumulan y derrochan experiencias (las monedas de oro del poeta), mediante acciones colectivas e improductivas ante los ojos del mercado y de la cultura dominante (Cusicanqui, 2015:144-145). Volver a mirar desde estas lógicas, que son sin duda también una experiencia cercana a lo «originario», nos abre el camino y, por lo tanto, el mapa. En palabras de Rosita, habitante de Cura Malal que fue entrevistada por el Proyecto Hermosura, «Un horizonte es otro horizonte, no se va en bicicleta tan rápido» (en Resch, Rosemberg, Suanno). Tanto ella como la comunidad de centinelas que habitan en ese rincón de la provincia de Buenos Aires saben que entre los ramales de la poesía y del arte no hay alambres. La mirada desde el archivo, entonces, debe tener la fuerza para seguir abriendo. Las acciones comunitarias, la fuerza del tren en marcha para seguir resistiendo. Las luciérnagas y los trenes, de este modo, no habrán muerto.

\section{Notas}

1 Ver https://www.lacapital.com.ar/informacion-gral/lagobernadora-vidal-cerro-47-escuelas-rurales-subajo-numeroalumnos-n1561621.html

2 Dinámica de vinculación social que los pueblos originarios del noroeste norteamericano practicaban, por la cual la adquisición o intercambio de objetos no respondió a la necesidad de adquirir, como se llevaba a cabo en la economía clásica a través del trueque, sino a la necesidad contraria de perder o de derrochar. Dicha práctica fue motivo de estudio por parte de George Bataille, quien toma como dispositivo de lectura este "potlatch" para pensar los modos en que la noción de «gasto» y «derroche» en la

cultura construyen «valores de cambio» alternativos a los configurados por la economía capitalista. Este "potlatch» también fue un leitmotiv de escritura para el poeta Arturo Carrera, quien en el año 2004 publica un poemario con dicho nombre como títuloy al que más adelante hacemos referencia mediante una cita.

3 En palabras del crítico Raúl Antelo: la archifilología puede reunir objetos, tiempos y espacios disímiles, atendiendo en cada caso a sus propios contextos, con el fin de encontrar en esas distancias una suma de vestigios de experiencias del pasado que deben ser resignificadas a la luz de las urgencias del presente (2015, S/N).

\section{Referencias bibliográficas}

Andermann, J. (2018). Tierras en trance. Arte y naturaleza después del paisaje. Santiago de Chile: Metales pesados.

Antelo, R. (2015). Reinventar la filología. Entrevista a Raúl Antelo por Editorial Eduvim. http://www.eduvim. com.ar/blog/reinventar-la-filologia-entrevista-raul-antelo

Arzac, A. y Stedille Luna, V. (2013). Dossier «Historias del oeste». Estructura mental a las estrellas, (5). 
Bataille, G. (2007). La parte maldita. Buenos Aires: Las cuarenta.

Carrera, A. (2008). Las cuatro estaciones. Buenos Aires: Mansalva. (2004). Potlatch. Buenos Aires: Interzona.

Cusicanqui, S.R. (2015). Sobre la comunidad de afinidad y otras reflexiones para hacernos y pensarnos en un mundo otro. El Aplante. Revista de estudios comunitarios, (1). Número especial «Común, ¿para qué?», 141-169. (2014). Ch’Ixinakax utxiwa. Una reflexión sobre prácticas y discursos colonizadores. Buenos Aires: Tinta limón.

Derrida, J. (2013). Archivo y borrador. En Goldchluk, G. y Pené, M. (Comp.). Palabras de archivo. Santa Fe, Argentina/Poitiers, Francia: Ediciones UNL/CRLA Archivos.

Didi-Huberman, G. (2009). Survivance des lucioles. París: Le Éditions de Minuit.

Laddaga, R. (2010). Estética de la emergencia: La formación de otra cultura de las artes. Buenos Aires: Adriana Hidalgo.

Link, D. (2008). La estación neobarroca. En Carrera, A. Las cuatro estaciones. Buenos Aires: Mansalva, 107-109.

Rasic, M.E. (2018). La poesía de Arturo Carrera: un archivo en obra. Tesis doctoral. http://sedici.unlp.edu.ar/ handle/10915/72150

Resch, M.; Rosemberg, N. y Suanno, V. (2008-2014). Proyecto Hermosura. Coronel Suárez, Buenos Aires: Publicación abierta y autogestiva con apoyo institucional de la Municipalidad y el Instituto Cultural de Coronel Suárez.

Rodríguez, F. (2010). Un desierto para la nación. La escritura del vacío. Buenos Aires: Eterna Cadencia.

\section{Sitios web de referencia utilizados}

«Proyecto Hermosura». Blog. http://proyectohermosura.blogspot.com/

«Estación Pringles: centro de utopías realizables en la pampa húmeda». http://www.estacionpringles.org.ar/ «La Tranca Cura Malal. Espacio de arte». Recuperado de Facebook.

«La gobernadora Vidal cerró 47 escuelas rurales por su bajo número de alumnos», en Diario La capital. Viernes 23 de febrero del 2018. https://www.lacapital.com.ar/informacion-gral/la-gobernadora-vidalcerro-47-escuelas-rurales-subajo-numero-alumnos-n1561621.html 